[Article]

www.whxb.pku.edu.cn

\title{
$\mathrm{ZnO}$ 氧缺陷的电子结构和光学性质
}

\author{
成 丽 $^{1}$ 张子英 ${ }^{1,2,3, *}$ 邵建新 ${ }^{1}$ \\ ('石河子大学师范学院物理系, 生态物理重点实验室, 新疆石河子 832003 ; 2复旦大学材料科学系, 上海 200433; \\ 新疆凝聚态相变与微结构实验室, 新疆 伊宁 835000)
}

摘要：采用基于密度泛函理论的平面波超软赝势方法对 $\mathrm{ZnO}_{0.875}$ 的电子结构和光学性质进行了计算. 用第一性 原理对含氧空位的 $\mathrm{ZnO}$ 晶体进行了结构优化处理, 计算了完整的和含氧空位的 $\mathrm{ZnO}$ 晶体的电子态密度. 结合 精确计算的电子态密度分析了带间跃迁占主导地位的 $\mathrm{ZnO}_{0.875}$ 材料的介电函数、吸收系数、折射系数、湮灭系数 和反射系数, 并对光学性质和极化之间的联系做了详细讨论. 结果表明 $\mathrm{ZnO}_{0.875}$ 晶体是单轴晶体, 并且在低能区 域存在因氧缺陷而造成的一些特性. 我们的研究结果为 $\mathrm{ZnO}$ 的发光特性提供新的视野, 同时为 $\mathrm{ZnO}$ 的光电子 材料的设计和应用提供理论基础.

关键词：密度泛函理论；电子结构；光学性质；氧缺陷

中图分类号: 0641

\section{Electronic Structures and Optical Properties of the O Vacancy in ZnO}

\author{
CHENG Li $\quad$ ZHANG Zi-Ying ${ }^{1,2,3, *} \quad$ SHAO Jian-Xin ${ }^{1}$
}

('Key Laboratory of Ecophysics, Department of Physics, Normal College, Shihezi University, Shihezi 832003, The Xinjiang Uygur Autonomous Region, P. R. China; ${ }^{2}$ Department of Materials Science, Fudan University, Shanghai 200433, P. R. China;

${ }^{3}$ Key Laboratory of Phase Transitions and Microstructures of Condensed Matters in Xinjiang, Yining 835000,

The Xinjiang Uygur Autonomous Region, P. R. China)

\begin{abstract}
The electronic structures and optical properties of $\mathrm{ZnO}_{0.875}$ were calculated by the ultra-soft pseudo-potential plane wave (pp-pw) method based on density functional theory. The crystal structure of $\mathrm{ZnO}$ with oxygen vacancies was optimized using first-principles. The electronic-state densities in pure $\mathrm{ZnO}$ and $\mathrm{ZnO}_{0.875}$ were then calculated. The dielectric functions, absorption spectrum, refractive index, extinction coefficient, and reflectivity of $\mathrm{ZnO}_{0.875}$ dominated by electron inter-band transitions were analyzed in terms of the precisely calculated density of state and the polarization dependencies of the optical properties were discussed in detail. Results indicate that the $\mathrm{ZnO}_{0.875}$ crystal is a uniaxial crystal and exhibits some features in the low energy region, which are caused by the $O$ vacancy. Our results provide new insights into the study of the luminescent behavior of $\mathrm{ZnO}$ and offer theoretical data for the design and application of $\mathrm{ZnO}$ optoelectronic materials.
\end{abstract}

Key Words: Density functional theory; Electronic structure; Optical property; O vacancy

\section{Introduction}

$\mathrm{ZnO}$ is a kind of classical semiconductor materials with a wide band gap of $3.3 \mathrm{eV}$ and a large exciton binding energy of
$60 \mathrm{meV}^{1-4}$ and shows potential application in varistors and optical devices. In order to design novel semiconductor materials, considerable theoretical efforts have been devoted to determine

Received: November 9, 2010; Revised: December 21, 2010; Published on Web: February 15, 2011.

"Corresponding author. Email: zzying25@yahoo.cn; Tel: +86-13052326692.

The project was supported by the National Natural Science Foundation of China (61065006) and the Open Project of Xinjiang Laboratory of Phase

Transitions and Microstructures of Condensed Matters, China (XJDX0912-2010-06).

国家自然科学基金(61065006)和新疆凝聚态相变与微结构实验室开放课题(XJDX0912-2010-06)资助项目

(C) Editorial office of Acta Physico-Chimica Sinica 
the electronic and optical properties of $\mathrm{ZnO}$ system materials. ${ }^{5-8}$ The luminescence property of $\mathrm{ZnO}$ has been investigated for several decades, but the centers and mechanisms responsible for its luminescence properties are still a matter of controversy. To explain the green luminescence, which has been known for several decades, various models have been proposed, including the involvement of $\mathrm{O}$ vacancies, ${ }^{9-11} \mathrm{O}$ interstitials, ${ }^{12,13} \mathrm{Zn}$ vacancies and $\mathrm{Zn}$ interstitials, ${ }^{14}$ or even substitutional $\mathrm{Cu} .{ }^{15}$ Recently, more and more investigative results reveal that the green photoluminescence behavior of $\mathrm{ZnO}$ may be attributed to $\mathrm{O}$ vacancies, which is thought to be abundant in crystal materials. ${ }^{9-11}$ Most of the present work was concerned with the crystal and band structures as well as mechanical properties. However, there have been very few reports on the calculations of the optical properties of $\mathrm{ZnO}$ with $\mathrm{O}$ vacancy, even though they are very important for understanding $\mathrm{ZnO}$ materials and their applications up to the present.

In this paper, we focused on the optical properties of $\mathrm{ZnO}$ crystal related to $\mathrm{O}$ vacancy using the pseudo-potential plane wave (pp-pw) method. The dielectric functions, absorption spectrum, refractive index, extinction coefficient, and reflectivity of $\mathrm{ZnO}_{0.875}$ dominated by electron inter-band transitions were analyzed in terms of the precisely calculated density of state. The polarization dependencies of those optical properties were discussed detailedly.

\section{Calculation method}

First-principles calculations were performed using the Materials Studio 4.1 graphical frontend interface using the Cambridge Serial Total Energy (CASTEP) code. ${ }^{16,17}$ For the CASTEP computer code, the Kohn-Sham equations were solved within the framework of density functional theory ${ }^{18}$ by expanding the wave functions of the valence electrons in a basis set of plane waves with a kinetic energy smaller than a specified cut-off energy, $E_{\text {cut }}$. The presence of tightly-bound core electrons was represented by non-local ultra-soft pseudo-potentials of the Vanderbilt-type. ${ }^{19}$ The states of $\mathrm{Zn} 3 d^{10} 4 s^{2}$ and $\mathrm{O}$ $2 s^{2} 2 p^{4}$ were treated as valence states. For crystal reciprocal-lattices, integration over the symmetrized Brillouin zone was performed by summing over special $k$-points that were generated from the Monkhorst-Pack scheme. ${ }^{20}$ A plane wave cut-off energy of $380 \mathrm{eV}$ and a $6 \times 6 \times 5$ grid of Monkhorst-Pack points were employed in this study to ensure good convergence between the computed structures and energies. Structural parameters for $\mathrm{ZnO}_{0.875}$ were determined using Broyden-Fletcher-GoldfarbShenno (BFGS) minimization technique with the following thresholds for converged structures, energy change per atom of less than $2 \times 10^{-5} \mathrm{eV}$, residual force of less than $0.1 \mathrm{eV} \cdot \mathrm{nm}^{-1}$, a stress of less than $0.03 \mathrm{GPa}$, and an atom displacement during the geometry optimization of less than $0.5 \times 10^{-4} \mathrm{~nm}$.

Optical properties were determined using the complex dielectric function $\varepsilon(\omega)=\varepsilon_{1}(\omega)+\mathrm{i} \varepsilon_{2}(\omega)$. The imaginary part of the dielectric function is given as: ${ }^{21}$

$$
\begin{aligned}
\varepsilon_{2}(\omega)= & \frac{V e^{2}}{2 \hbar m^{2} \omega^{2}} \int \mathrm{d}^{3} \boldsymbol{k} \sum_{n n^{\prime}}\left|\left\langle\boldsymbol{k} n|\boldsymbol{p}| \boldsymbol{k} n^{\prime}\right\rangle\right|^{2} \times \\
& f(\boldsymbol{k} n)\left(1-f\left(\boldsymbol{k} n^{\prime}\right) \delta\left(E_{\boldsymbol{k} n}-E_{\boldsymbol{k} n^{\prime}}-\hbar \omega\right)\right.
\end{aligned}
$$

where $\boldsymbol{p}$ is the momentum operator, $e$ is the electronic charge, $V$ is the volume, $\omega$ is the light frequency, $\hbar \omega$ is the energy of the incident phonon, $m$ is electronic mass, $|\boldsymbol{k} n\rangle$ and $\left|\boldsymbol{k} n^{\prime}\right\rangle$ are the conduction band (CB) and valence band (VB) wave functions corresponding to the $n$th and $n$ 'th eigenvalue with crystal momentum $\boldsymbol{k}$, and $f(\boldsymbol{k} n)$ is the Fermi distribution function. Evaluation of the matrix elements of the momentum operator in Eq. (1) was carried out over the muffin-tin and the interstitial regions separately. Further details about the evaluation of matrix elements can be found in literature. ${ }^{21}$ The real part of the dielectric function can be derived from the imaginary part using the Kramers-Kronig relations. ${ }^{21}$

$$
\varepsilon_{1}(\omega)=1+\frac{2}{\pi} q \int_{0}^{\infty} \frac{\varepsilon_{2}\left(\omega^{\prime}\right) \omega^{\prime} d \omega^{\prime}}{\omega^{\prime 2}-\omega^{2}}
$$

where $q$ is the principal value of the integral. The knowledge of both the real and imaginary parts of the dielectric function allows the calculation of important optical functions. Expressions for the absorption coefficient $I(\omega)$, refractive index $n(\omega)$, extinction coefficient $k(\omega)$, reflectivity $R(\omega)$, and energy-loss spectrum $L(\omega)$ can be calculated using the dielectric function through the following relations $:^{19,22,23}$

$$
\begin{aligned}
& I(\omega)=\sqrt{2} \omega\left[\sqrt{\varepsilon_{1}(\omega)^{2}+\varepsilon_{2}(\omega)^{2}}-\varepsilon_{1}(\omega)\right]^{\frac{1}{2}} \\
& n(\omega)=\left[\frac{\varepsilon_{1}(\omega)}{2}+\frac{\sqrt{\varepsilon_{1}(\omega)^{2}+\varepsilon_{2}(\omega)^{2}}}{2}\right]^{\frac{1}{2}} \\
& k(\omega)=\sqrt{\frac{1}{2}}\left[\sqrt{\varepsilon_{1}(\omega)^{2}+\varepsilon_{2}(\omega)^{2}}-\varepsilon_{1}(\omega)\right]^{\frac{1}{2}} \\
& R(\omega)=\left|\frac{\sqrt{\varepsilon(\omega)}-1}{\sqrt{\varepsilon(\omega)+1}}\right|^{2} \\
& L(\omega)=\frac{\varepsilon_{2}(\omega)}{\varepsilon_{1}(\omega)^{2}+\varepsilon_{2}(\omega)^{2}}
\end{aligned}
$$

The calculation of optical properties usually requires a dense mesh of uniformly distributed $k$-points. We employed Brillouin zone integration with a $20 \times 20 \times 20$ grid of Monkhorst-Pack points to the calculation.

\section{Results and discussion}

$\mathrm{ZnO}$ has a hexagonal wurtzite structure belonging to $P 63 m c$ space group. The unit cell contains two $\mathrm{Zn}$ cations and two $\mathrm{O}$ anions. The lattice parameters are the second nearest neighbour distances: $a=0.3258 \mathrm{~nm}, c=0.522 \mathrm{~nm}, \alpha=\beta=90^{\circ}, \gamma=120^{\circ}$ and the ratio $c / a=1.602 .^{24,25}$ In order to study the fractional $\mathrm{O}$ vacancy in $\mathrm{ZnO}$, we considered a cell larger than the basic unit. Thus we constructed a $2 \times 2 \times 1$ super-cell consisting of 16 atoms, as displayed in Fig.1. Firstly, the properties of pure $\mathrm{ZnO}$ wurtzite structure with $2 \times 2 \times 1$ super-cell were calculated for testing the validity of the method, the optimal lattice constants of pure $\mathrm{ZnO}$ are: $a=0.3267 \mathrm{~nm}, c=0.5228 \mathrm{~nm}$, respectively, which are slightly beyond the experimental values. ${ }^{24,25}$ This overestima- 


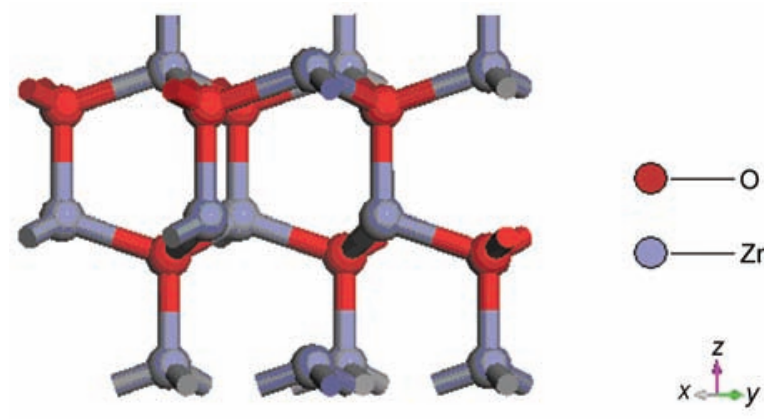

Fig.1 Super cell model of $\mathrm{ZnO}_{0.875}$

tion of the lattice constants based on the GGA method is reasonable.

Fig.2(a, b) show the density of states (DOSs) of pure $\mathrm{ZnO}$ and $\mathrm{ZnO}_{0.875}$, respectively. The DOSs in Fig.2(b) indicate that $\mathrm{CBs}$ of $\mathrm{ZnO}_{0.875}$ originate mainly from the cooperative contributions of $\mathrm{O} 2 p, \mathrm{Zn} 4 s$, and $\mathrm{Zn} 3 d$ orbitals, among which $\mathrm{Zn}$ atoms are dominant. VBs between -20.0 and $-15.0 \mathrm{eV}$ are derived from $\mathrm{O} 1 s$ orbital. The major contributions to VBs be-
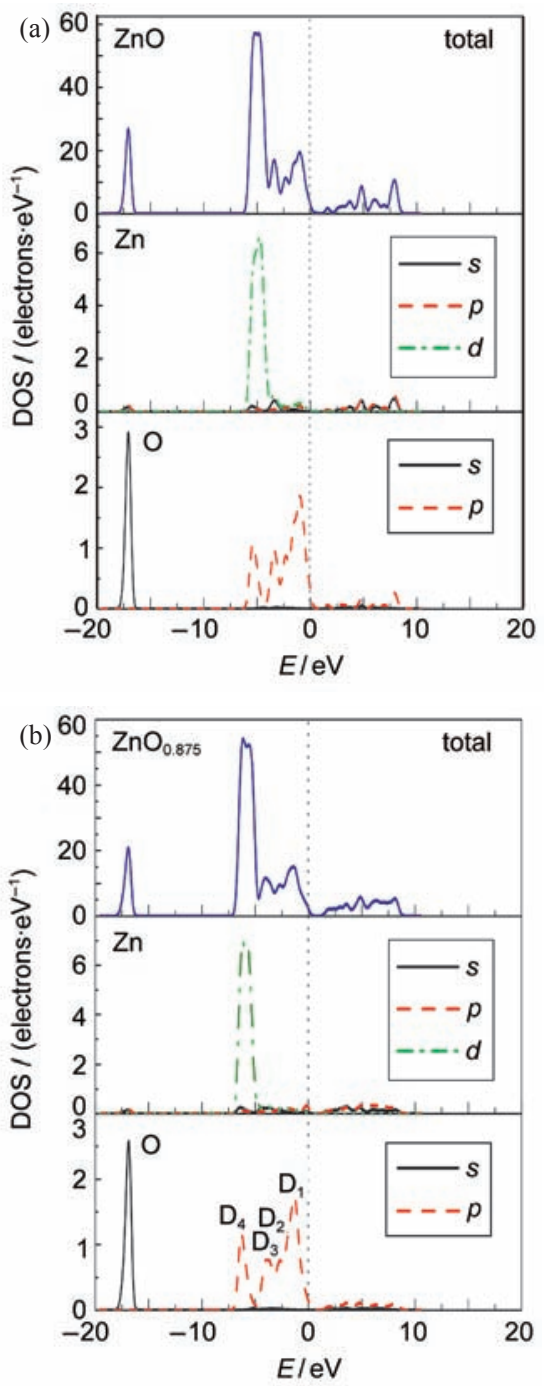

Fig.2 Calculated total and partial density of states (DOSs) for pure $\mathrm{ZnO}$ (a) and $\mathrm{ZnO}_{0.875}$ (b) as a function of the photon energy tween -7.5 and $-5.0 \mathrm{eV}$ are mainly from $\mathrm{Zn} 3 d$ and $\mathrm{O} 2 p$ orbitals. The upper valence bands from -5.0 to $0.0 \mathrm{eV}$ are composed of $\mathrm{O} 2 p$ states. The overall DOS features remain approximately similar to those of pure $\mathrm{ZnO}$. However, compared with those of pure $\mathrm{ZnO}, \mathrm{Zn} 3 d$ and $\mathrm{O} 2 p$ states of $\mathrm{ZnO}_{0.875}$ shift to lower energy range and a new peak of $\mathrm{Zn} 3 p$ orbitals appears in the vicinity of the Fermi energy. Those differences caused by electron deficiency will strongly affect the optical properties.

Dielectric function $\varepsilon(\omega)$, which describes the features of linear response of the system to an electromagnetic radiation, governs the propagation behavior of radiation in a medium. $\varepsilon(\omega)$ is connected with the interaction of photons with electrons. Optical constants, such as refractive index $n(\omega)$, absorption coefficient $\alpha(\omega)$, reflectivity $R(\omega)$, and electron energy-loss spectrum $L(\omega)$, can be deduced from $\varepsilon_{1}(\omega)$ and $\varepsilon_{2}(\omega) .^{19,23}$ As supportive evidence, we calculated $\varepsilon_{1}(\omega)$ and $\varepsilon_{2}(\omega)$ of the known pure $\mathrm{ZnO}$ and the results were in good agreement with the experimental data, ${ }^{26}$ as shown in Fig.3.

Fig. 4 shows the calculated $\varepsilon_{1}(\omega)$ and $\varepsilon_{2}(\omega)$ of $\mathrm{ZnO}_{0.875}$. First, we discussed the case of incident radiation with the liner polarization along the (001) direction. It can be seen from Fig.4 that

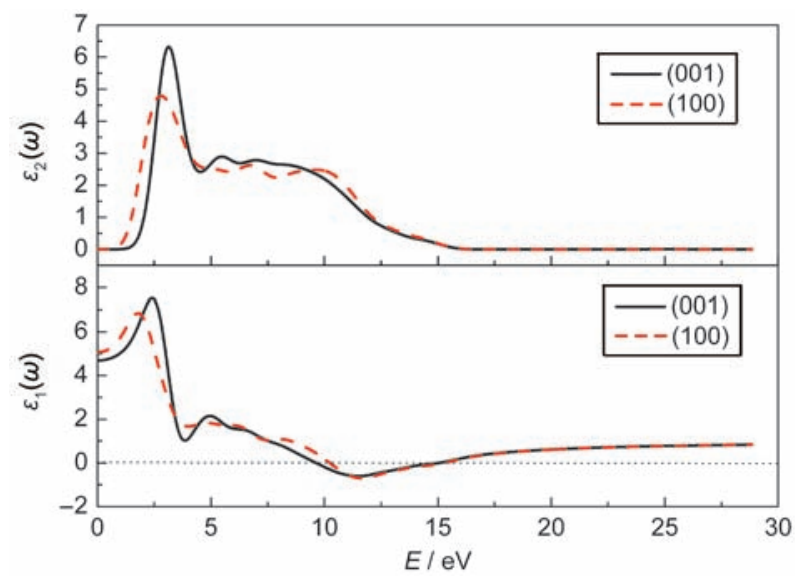

Fig.3 Calculated dielectric function $\varepsilon(\omega)$ of pure $\mathrm{ZnO}$ as a function of the photon energy

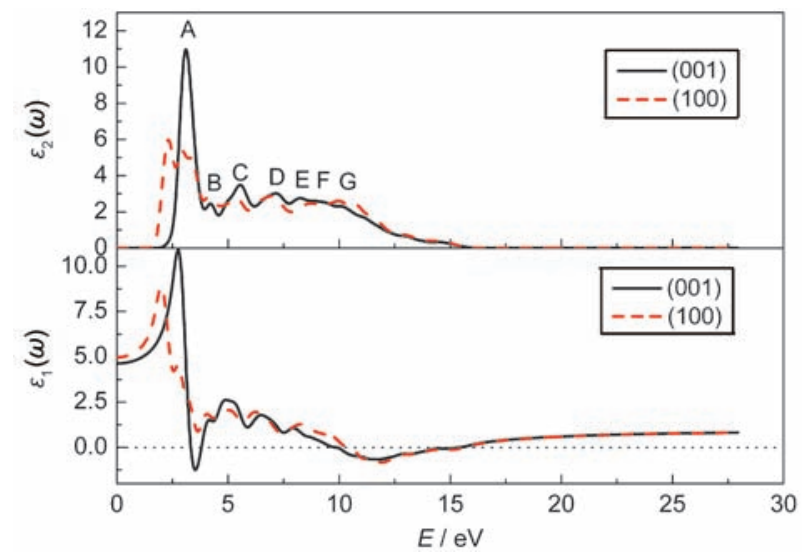

Fig.4 Calculated dielectric function $\varepsilon(\omega)$ of $\mathrm{ZnO}_{0.875}$ as a function of the photon energy 


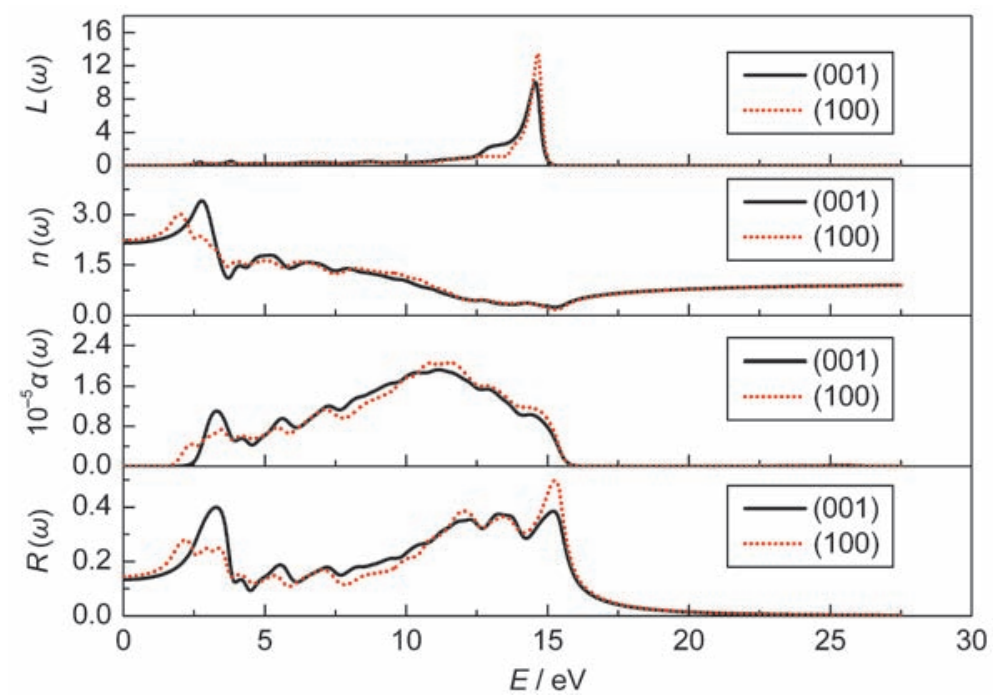

Fig.5 Calculated dispersive properties of optical constants of $\mathrm{ZnO}_{0.875}$ as a function of the photon energy $L(\omega), n(\omega), \alpha(\omega)$, and $R(\omega)$ stand for energy-loss spectrum, refractive index, absorption coefficient, and reflectivity, respectively.

the real part $\varepsilon_{1}(\omega)$ increases with the increase of energy, and then reaches a maximum at $2.67 \mathrm{eV}$ in the low energy region, which can be reflected from the first reflectivity peak in Fig.5. The imaginary part $\varepsilon_{2}(\omega)$ of the dielectric function has seven prominent peaks: A $(3.15 \mathrm{eV}), \mathrm{B}(4.24 \mathrm{eV}), \mathrm{C}(5.56 \mathrm{eV}), \mathrm{D}$ (7.19 eV), E (8.36 eV), F (9.25 eV), and G (10.25 eV). Peaks $\mathrm{A}, \mathrm{B}$, and $\mathrm{C}$ mainly correspond to the transition from $\mathrm{O} 2 p$ VBs, derived from the peaks $D_{1}, D_{2}$, and $D_{3}$ in the partial density of state (Fig.2(b)), respectively, to the unoccupied CBs. Peak D mainly originates from the transition from $\mathrm{Zn} 3 d$ and $\mathrm{O}$ $2 p$ VBs to $\mathrm{O} 2 p$ or $\mathrm{Zn} 4 s \mathrm{CBs}$, for which evidence can be found in the partial density of state. Peaks $\mathrm{E}$ and $\mathrm{F}$ are assigned to the transition of inner electrons from $\mathrm{O} 2 s$ orbitals to the $\mathrm{Zn}$ $3 d$ or O $2 p$ VBs. The peaks and the corresponding transitions in the case of (100) polarization remain approximately similar to those mentioned above. However, a new peak occurs at 2.26 $\mathrm{eV}$, which may belong to the transition from $\mathrm{Zn} 3 p$ to CBs and cause emission of the green photoluminescence. Though the emission of the green photoluminescence has been reported to have an energy centered at $2.33 \mathrm{eV}$ by Li et al., ${ }^{27}$ our data are reasonable because of the tendency of underestimate of energyband for GGA in solid state physics.

The optical properties, such as refractive index $n(\omega)$, absorption coefficient $\alpha(\omega)$, reflectivity $R(\omega)$, and electron energyloss spectrum $L(\omega)$, are given in Fig.5. We found that the refractive indices along the (001) and (100) polarization directions, $n_{(001)}$ and $n_{(100)}$, exhibit slight difference. Almost all the peaks appeared in $n_{(001)}$ are recurred in $n_{(100)}$ at the same point. However, $n_{(100)}$ is found to have a new peak at $2.02 \mathrm{eV}$. All the peaks appeared in spectrum of refractive index are related to the peaks appeared in the imaginary part of the dielectric function. Those also indicate that, supposing that the polarization direction is perpendicular to the (100) direction, all the refractive indices are equivalent to $n_{(001)}$. From the viewpoint of crys- tal optics, this special direction (100) is distinguished and regarded as the optical axis, suggesting that the $\mathrm{ZnO}_{0.875}$ crystal belongs to the uniaxial crystal. The $\mathrm{ZnO}_{0.875}$ crystal may become transparent in the high energy region, because it is found that the electrons are harder to respond. The calculated linear absorption spectrum is also shown in Fig.5. The absorption edge polarized along (001) direction starts at about $2.30 \mathrm{eV}$. This originates from the transition from $\mathrm{O} 2 p$ electron states located at the top of the valence bands to the empty $\mathrm{Zn} 3 d$ electron states that dominate the bottom of the conduction bands. The first peak in the absorption spectrum is at $3.29 \mathrm{eV}$. Other peaks in low energy region are at 4.24, 5.61, 7.25, 8.25, and $9.40 \mathrm{eV}$, respectively. According to the results of calculated dielectric function, the energy of each absorption peak is almost due to the transition of electron excitation from the VBs to the CBs. The absorption polarized along (100) direction starts at about $1.71 \mathrm{eV}$ and increases with the increasing photon energy with a new peak appeared at $2.30 \mathrm{eV}$, which mainly corresponds to the transition from $\mathrm{Zn} 3 p$ VB to O $2 p$ or $\mathrm{Zn} 4 s$ CBs. The energy loss spectrum $L(\omega)$ is an important factor describing the energy loss of a fast electron traversing in a material. The peaks in $L(\omega)$ spectrum represent the characteristic associated with the plasma oscillation and the corresponding frequencies are the so-called bulk plasma frequencies $\omega(p)$, above which the material is a dielectric $\left[\varepsilon_{1}(\omega)\right.$ is positive] while below which the material behaves as a metallic $\left[\varepsilon_{1}(\omega)\right.$ is negative $].^{28}$ In the case of (001) polarization, there are a strong peak at $14.58 \mathrm{eV}$ and a weak one at $3.87 \mathrm{eV}$ in $L(\omega)$ spectra, while there is a single strong peak at $14.69 \mathrm{eV}$ in the case of (100) polarization. The results of the calculated $L(\omega)$ spectrum are in good agreement with the feature of $\varepsilon_{1}(\omega)$ shown in Fig.4. The peaks of $L(\omega)$ correspond to the trailing edges in the reflection spectra. The prominent peaks of $L(\omega)$ locate at the energies correspond to the abrupt reduction of $R(\omega)$. 


\section{Conclusions}

The electric structures and optical properties of $\mathrm{ZnO}_{0.875}$ were studied in detail using the pseudo-potential plane wave (pp-pw) method. The calculations show that the electron structures between $\mathrm{ZnO}_{0.875}$ and $\mathrm{ZnO}$ have some obvious differences. Combining the calculations of optical parameters of $\mathrm{ZnO}_{0.875}$, the differences of electron structures between $\mathrm{ZnO}_{0.875}$ and $\mathrm{ZnO}$ may cause the green photoluminescence. The dielectric function and the dispersion properties of optical constants, such as the refractive index, absorption coefficient, electron energyloss spectrum, and reflectivity, were also presented. The calculations show that the $\mathrm{ZnO}_{0.875}$ crystal is uniaxial crystal and exhibits some features in the low energy region caused by the $\mathrm{O}$ vacancy. These results provide new insights to the study of the luminescent behavior of $\mathrm{ZnO}$ and offer theoretical data for the design and application of optoelectronic materials of $\mathrm{ZnO}$.

\section{References}

(1) Rebien, M.; Henrion, W.; Bär, M.; Fischer, C. H. Appl. Phys. Lett. 2002, 80, 3518.

(2) Huang, M. H.; Mao, S.; Feick, H.; Yan, H.; Wu, Y.; Kind, H.; Weber, E.; Russo, R.; Yang, P. Science 2001, 292, 1897.

(3) Pan, Z. W.; Dai, Z. R.; Wang, Z. L. Science 2001, 291, 1947.

(4) Lambrecht, W. R. L.; Rodina, A. V.; Limpijumnong, S.; Segall, B.; Meyer, B. K. Phys. Rev. B 2002, 65, 075207.

(5) Xiong, Z. H.; Jiang, F. H. J. Phys. Chem. Solids 2007, 68, 1500.

(6) Mounkachi, O.; Benyoussef, A.; El Kenz, A.; Saidi, E. H.; Hlil, E. K. J. Magn. Magn. Mater. 2008, 320, 2760.

(7) Chang, G. S.; Kurmaev, E. Z.; Boukhvalov, W.; Finkelstein, L. D.; Colis, S.; Pedersen, T. M.; Moewes, A.; Dinia, A. Phys. Rev. B 2007, 75, 195215.

(8) Sun, Y. M.; Wang, H. Z. Physica B 2003, 325, 157.

(9) Kasai, P. H. Phys. Rev. 1963, 130, 989.
(10) Kröger, F. A.; Vink, H. J. J. Chem. Phys. 1954, 22, 250.

(11) Prosanov, I. Y.; Politov, A. A. Inorg. Mater. 1995, 31, 663.

(12) Hahn, D.; Nink, R. Physik der Kondensiterten Materie 1965, 3, 311.

(13) Liu, M.; Kitai, A. H.; Mascher, P. J. Lumin. 1992, 54, 35.

(14) Bylander, E. G. J. Appl. Phys. 1978, 49, 1188.

(15) Dingle, R. Phys. Rev. Lett. 1969, 23, 579.

(16) Payne, M. C.; Teter, M. P.; Allan, D. C.; Arias, T. A.; Joannopoulos, J. D. Rev. Mod. Phys. 1992, 64, 1045.

(17) Segall, M. D.; Lindan, P. J. D.; Probert, M. J.; Pickard, C. J.; Hasnip, P. J.; Clark, S. J.; Payne, M. C. J. Phys. Condens. Matter 2002, 14, 2717.

(18) Ghosez, P.; Desquesnes, D.; Gonze, X.; Rabe, K. M. AIP Conf. Proc. 2000, 535, 102.

(19) Saha, S.; Sinha, T. P. Phys. Rev. B 2000, 62, 8828.

(20) Monkhorst, H. J.; Pack, J. D. Phys. Rev. B 1976, 13, 5188.

(21) Ambrosch-Draxl, C.; Sofo, J. O. Comput. Phys. Commun. 2006, 175,1 .

(22) Zhang, Z. Y.; Yang, D. L.; Liu, Y. H.; Cao, H. B.; Shao, J. X.; Jing, Q. Acta Phys. -Chim. Sin. 2009, 25, 1731. [张子英, 杨德 林, 刘云虎, 曹海滨, 邵建新, 井 群. 物理化学学报, 2009, 25, 1731.]

(23) Cai, M. Q.; Yin, Z.; Zhang, M. S. Appl. Phys. Lett. 2003, 83, 2805 .

(24) Kohan, A. F.; Ceder, G.; Morgan, D.; Van de Walle, C. G. Phys. Rev. B 2000, 61, 15019 .

(25) Decremps, F.; Datchi, F.; Saitta, A. M.; Polian, A. Phys. Rev. B 2003, 68, 104101.

(26) John, L. F. Phys. Rev. B 1973, 7, 3810.

(27) Li, H. X.; Wang, R. H.; Guo, C. H.; Zhang, H. Mater. Sci. Eng. $B$ 2003, 103, 285.

(28) De Almeida, J. S.; Ahuja, R. Phys. Rev. B 2006, 73, 165102 